\title{
THE PROPOSAL OF A TARIFF TAKING INTO ACCOUNT THE RISK FROM UNOCCUPIED CAPACITY OF PASSENGER TRAINS
}

There are many different views on perceived benefits and costs of the offered transport services in the market, because each customer gives a different weight to characteristics of these services. The customer thus buys a service from the transport company that offers the highest perceived benefits in relation to the total cost. Therefore it is important to monitor traffic flows of passengers in a long-distance rail passenger transport and in advance specify the expected number of passengers who use this link. Only on the basis of a well-prepared prediction it will be possible to establish an effective session tariff, which ensures reimbursement of all costs to the carrier and also guarantees a reasonable profit. The aim of this paper is to provide a cost analysis of a carrier in passenger rail transport at the risk of unoccupied capacity of a selected train in different variants of its workload and the proposal of a session tariff with respect to this risk.

Keywords: Passenger transport, capacity, risk, calculation of costs.

\section{Introduction}

The term "risk" has many meanings, and is differently defined in the scientific literature, legal norms and various dictionaries. The meaning of this term depends on the field of activity, for which it is defined, on the purpose of the risk definition, and on its subsequent use.

Rail transport as a whole is affected by a number of risks that may arise in different parts of the process and may diversely affect various entities involved in the transport. Risk is defined as an opportunity that it will become something that has an impact on the goals, and is measured by the consequences or an estimate of the probability [1 and 2].

\section{Risk from unoccupied capacity of a selected passenger train}

Risk from unoccupied capacity is one of many risks in the rail passenger transport which may cause a reduction in profit to the carrier, even the incomplete payment of its costs and subsequent loss. This is the risk, when the carrier shares the loss in the operation of passenger rail transport arising from circumstances that can occur before the transport or during the process of transport and that are not included in the final price of transport [3 and 2].

\section{Cost analysis for a selected train}

Knowing the costs of operations and processes is an essential tool of economic management in the company. In the market environment it is necessary to monitor the costs in several ways. Calculation of own costs in the company should be adapted to the opportunity to analyse and plan the costs for individual activities and processes. Currently, the cost calculations are assigned to the controlling system and are known as cost controlling. It is a broader term which includes not only the monitoring of the costs actually incurred in the activities and processes, but also their planning and control, i.e. we can talk about the cost management in the company [4 and 5].

Total own costs for transport by rail can be calculated according to the formulas that take into account indicators of transport work and relevant cost rates. The basic formula may have the form [4 and 6]:

$C_{t}^{\text {total }}=C_{W}+C_{l}+C_{t c}+C_{l c}+C_{r i}+C_{e}+C_{i}$

\footnotetext{
* ${ }^{1}$ Lenka Cerna, ${ }^{1}$ Jozef Danis, ${ }^{2}$ Borna Abramovic

${ }^{1}$ University of Zilina, Faculty of Operation and Economics of Transport and Communications, Slovakia

${ }^{2}$ University of Zagreb, Faculty of Transport Traffic Sciences, Croatia

E-mail: jozef.danis@fpedas.uniza.sk
} 
where: $\mathrm{C}^{\text {total }}$ Total costs of a train

$C_{w}$ - Costs of carriages

$C_{l}$ - Costs of locomotives

$C_{t c}$ - Costs of the train crew

$C_{l c}$ - Costs of the locomotive crew

$C_{r i}$ - Costs of the rail infrastructure

$C_{e}$ - Costs of energy

$C_{i}$ - Indirect costs

In the introduction of the analysis of risk from unoccupied capacity of the selected passenger train its identification is important, i.e. detection of all possible effects that cause this risk. For the proper identification of the risk the detailed analysis of the costs which enter this process is significant. The risk identification and analysis of the costs are applied to a model example for the session Bratislava - Trencin - Zilina Poprad - Kosice with the configuration of the train: locomotive $131+$ Ampeer + WRRmeer + 6x Bmpeer [7 - 9]. All needed parameters of the model train are in Table 1.

Basic Parameters of the Model Passenger Train

Table 1

\begin{tabular}{|c|c|c|}
\hline $\begin{array}{c}\text { Configuration of the train } \\
\text { on the session BA - KE }\end{array}$ & Weight [t] & Places for seating \\
\hline 1x Ampeer & 49 & 54 \\
\hline 1x WRRmeer & 46 & 0 \\
\hline 6x Bmpeer & 44 & 76 \\
\hline Locomotive 363 & 87 & \multirow{2}{*}{510} \\
\hline Total gross weight & 446 & \\
\hline Distance [km] & $445 \mathrm{~km}$ & \multirow{2}{|}{} \\
\hline Infrastructure fee * & $€ 461.47$ & \\
\hline
\end{tabular}

* calculated with a calculator ZSR [10 and 11]

Division of costs is often modified by a calculation formula. The transport company may use more these formulas (e.g. for individual organisational units or for individual business areas). An essential aspect of the division of costs in the calculation formula is their division into direct and indirect costs [12 and 13]. Cost analysis for the model train is shown in Table 2.
The total costs of the model train from Bratislava via Zilina to Kosice are $€ 6,142.73$.

\section{The proposal of the tariff taking into account the diverse occupancy of the train}

The proposal of an optimal tariff ( $100 \%$ occupancy of seats) can be obtained based on the proportion of the total costs and total number of seats when we get the costs of one seat in the whole session. After rounding up the result to an integer, which constitutes a reasonable profit, and from the resulting price for transport over the entire session we will derive prices for transport in individual sections. This will be the basis for creating the relational tariff. The price for individual sections is formed with regards to the distance, but like with the entire session, the results are rounded up, and that should mean a reasonable profit for the carrier. Another form of profit growth is to propose a surcharge to the ticket in the first class, which would mean $€ 4$ / one seat.

Revenues are calculated through multiplying the number of occupied seats in the second class with the price for the transport throughout the whole session, plus revenues from the first class (the same way). At the formation of a tariff policy we take into account the fact that not all passengers do travel across the entire session; but the price for transport in the individual sections is higher, and thus the revenues of the carrier will not be reduced. The revenues are calculated as the lowest possible revenues at a given occupancy. Profit is calculated as the difference between revenues and costs (Table 3).

The prices for transport in individual sections are necessarily to be adjusted (raised) in order to cover the total costs also in case the occupancy is not $100 \%$. Total costs are unchanged with respect to occupancy. The calculations with variable occupancy of the train are shown in the following Tables 4 - 9 .

Calculation of the Costs for the Model Train

Table 2

\begin{tabular}{|l|l|}
\hline$\sum$ carriage kilometres $: 3,560$ & Costs of the carriages : $€ 2,848$ \\
\hline$\sum$ train kilometres : 445 & Costs of the locomotive $: € 289.25$ \\
\hline$\sum$ hourly rates for locomotive crew $: 6$ & Costs of the locomotive crew : €84 \\
\hline$\sum$ hourly rates for train crew $: 6$ & Costs of the train crew : $€ 330$ \\
\hline$\sum$ gross tonnage kilometres $(\mathrm{GTKM}): 105,198$ & Costs of the energy : $€ 287.19$ \\
\hline Specific consumption $(\mathrm{kWh} / 1,000 \mathrm{GTKM}): 18.2$ & Indirect costs $: € 1,842.82$ \\
\hline Travel time (hour) $: 5$ & Total costs of the train $: € 6,142.73$ \\
\hline
\end{tabular}

The total costs of the model train from Bratislava via Zilina to Kosice are $€ 6,142.73$. 


\section{COMMNICOIIONS}

The Proposal of a Tariff on the Session Bratislava - Kosice for 100\% Occupancy of the Model Train and the Costs of One Seat €12.0446 in the Entire Line

Table 3

Costs of one seat in the entire line are $€ 12.0446$.

\begin{tabular}{|l|c|c|c|c|c|c|c|c|}
\cline { 2 - 11 } \multicolumn{1}{c|}{$100 \%$ occupancy } & \multicolumn{2}{c|}{ TN } & \multicolumn{2}{c|}{ ZA } & \multicolumn{2}{c|}{ PP } & \multicolumn{2}{c|}{ KE } \\
\cline { 2 - 11 } \multicolumn{1}{c|}{} & 2. class & 1. class & 2. class & 1. class & 2. class & 1. class & 2. class & 1. class \\
\hline Bratislava & 5 & 9 & 7 & 11 & 11 & 15 & 13 & 17 \\
\hline Trencin &. &. & 3 & 7 & 8 & 12 & 10 & 14 \\
\hline Zilina &. &. &. &. & 5 & 9 & 8 & 12 \\
\hline Poprad &. &. &. &. &. &. & 3 & 7 \\
\hline
\end{tabular}

\section{Revenues: $€ 6,846$}

Profit: €703.27

The Original Tariff on the Session Bratislava - Kosice for 80\% Occupancy of the Model Train and the Costs of One Seat $€ 15.0557$ in the Entire Line

Original tariff with a lower occupancy $(80 \%)$ :

\begin{tabular}{|l|c|c|c|c|c|c|c|c|}
\cline { 2 - 10 } \multicolumn{1}{c|}{$80 \%$ occupancy } & \multicolumn{2}{c|}{ TN } & \multicolumn{2}{c|}{ ZA } & \multicolumn{2}{c|}{ PP } & \multicolumn{2}{c|}{ KE } \\
\cline { 2 - 11 } \multicolumn{1}{c|}{} & 2. class & 1. class & 2. class & 1. class & 2. class & 1. class & 2. class & 1. class \\
\hline Bratislava & 5 & 9 & 7 & 11 & 11 & 15 & 13 & 17 \\
\hline Trencin & $\cdot$ & $\cdot$ & 3 & 7 & 8 & 12 & 10 & 14 \\
\hline Zilina & $\cdot$ &. &. &. & 5 & 9 & 8 & 12 \\
\hline Poprad &. &. &. &. &. &. & 3 & 7 \\
\hline
\end{tabular}

\section{Revenues: $€ 5,476.8$}

\section{Loss: $€-665.93$}

The Changed Tariff on the Session Bratislava - Kosice for 80\% Occupancy of the Model Train and the Costs of One Seat $€ 15.0557$ in the Entire Line

Changed tariff with a lower occupancy $(80 \%)$ :

\begin{tabular}{|l|c|c|c|c|c|c|c|c|}
\cline { 2 - 10 } \multicolumn{1}{c|}{$80 \%$ occupancy } & \multicolumn{2}{c|}{ TN } & \multicolumn{2}{c|}{ ZA } & \multicolumn{2}{c|}{ PP } & \multicolumn{2}{c|}{ KE } \\
\cline { 2 - 11 } \multicolumn{1}{c|}{} & 2. class & 1. class & 2. class & 1. class & 2. class & 1. class & 2. class & 1. class \\
\hline Bratislava & 6 & 10 & 8 & 12 & 11 & 15 & 16 & 20 \\
\hline Trencin &. &. & 4 & 8 & 10 & 14 & 12 & 16 \\
\hline Zilina &. &. &. &. & 6 & 10 & 10 & 14 \\
\hline Poprad &. &. &. &. &. &. & 4 & 8 \\
\hline
\end{tabular}

Revenues after the change of rates: $€ 6,700.8$

Profit after the change of rates: $€ 558.07$

The Original Tariff on the Session Bratislava - Kosice for 60\% Occupancy of the Model Train and the Costs of One Seat €20.0743 in the Entire Line

Table 6

Original tariff with a lower occupancy $(60 \%)$ :

\begin{tabular}{|c|c|c|c|c|c|c|c|c|}
\hline \multirow[t]{2}{*}{$60 \%$ occupancy } & \multicolumn{2}{|l|}{$\mathrm{TN}$} & \multicolumn{2}{|l|}{ ZA } & \multicolumn{2}{|l|}{ PP } & \multicolumn{2}{|l|}{$\mathrm{KE}$} \\
\hline & 2. class & 1. class & 2. class & 1. class & 2. class & 1. class & 2. class & 1. class \\
\hline Bratislava & 6 & 10 & 8 & 12 & 11 & 15 & 16 & 20 \\
\hline Trencin & . & . & 4 & 8 & 10 & 14 & 12 & 16 \\
\hline Zilina & & . & . & & 6 & 10 & 10 & 14 \\
\hline Poprad & & . & . & . & . & . & 4 & 8 \\
\hline
\end{tabular}

Revenues: €5,025.6

Profit: €1,117.13 
The Changed Tariff on the Session Bratislava - Kosice for 60\% Occupancy of the Model Train and the Costs of One Seat €20.0743 in the Entire Line

Changed tariff with a lower occupancy $(60 \%)$ :

\begin{tabular}{|l|c|c|c|c|c|c|c|c|}
\cline { 2 - 10 } \multicolumn{1}{c|}{$\mathbf{6 0}$} & \multicolumn{2}{c|}{ TN occupancy } & \multicolumn{2}{c|}{ ZA } & \multicolumn{2}{c|}{ PP } & \multicolumn{2}{c|}{ KE } \\
\cline { 2 - 11 } \multicolumn{1}{c|}{} & 2. class & 1. class & 2. class & 1. class & 2. class & 1. class & 2. class & 1. class \\
\hline Bratislava & 7 & 11 & 11 & 15 & 11 & 15 & 21 & 25 \\
\hline Trencin & $\cdot$ &. & 5 & 9 & 13 & 17 & 15 & 19 \\
\hline Zilina & $\cdot$ &. &. &. & 7 & 11 & 13 & 17 \\
\hline Poprad &. &. &. &. &. &. & 5 & 9 \\
\hline
\end{tabular}

Revenues after the change of rates: $€ 6,555.6$

Profit after the change of rates: $€ 412.87$

The Original Tariff on the Session Bratislava - Kosice for 40\% Occupancy of the Model Train and the Costs of One Seat $€ 30.1114$ in the Entire Line

Original tariff with a lower occupancy (40\%):

\begin{tabular}{|l|c|c|c|c|c|c|c|c|}
\cline { 2 - 10 } \multicolumn{1}{c|}{$40 \%$ occupancy } & \multicolumn{2}{c|}{ TN } & \multicolumn{2}{c|}{ ZA } & \multicolumn{2}{c|}{ PP } \\
\cline { 2 - 10 } \multicolumn{1}{c|}{} & 2. class & 1. class & 2. class & 1. class & 2. class & 1. class & 2. class & 1. class \\
\hline Bratislava & 7 & 11 & 11 & 15 & 11 & 15 & 21 & 25 \\
\hline Trencin &. &. & 5 & 9 & 13 & 17 & 15 & 19 \\
\hline Zilina &. &. &. &. & 7 & 11 & 13 & 17 \\
\hline Poprad &. &. &. &. &. &. & 5 & 9 \\
\hline
\end{tabular}

Revenues: $€ 4,370.4$

Loss: $€-1,772.33$

The Changed Tariff on the Session Bratislava - Kosice for 40\% Occupancy of the Model Train and the Costs of One Seat $€ 30.1114$ in the Entire Line

Changed tariff with a lower occupancy (40\%):

\begin{tabular}{|l|c|c|c|c|c|c|c|c|}
\cline { 2 - 10 } \multicolumn{1}{c|}{$40 \%$ occupancy } & \multicolumn{2}{c|}{ TN } & \multicolumn{2}{c|}{ ZA } & \multicolumn{2}{c|}{ PP } & \multicolumn{2}{c|}{ KE } \\
\cline { 2 - 10 } \multicolumn{1}{c|}{} & 2. class & 1. class & 2. class & 1. class & 2. class & 1. class & 2. class & 1. class \\
\hline Bratislava & 11 & 15 & 16 & 20 & 11 & 15 & 31 & 35 \\
\hline Trencin &. &. & 7 & 11 & 19 & 23 & 22 & 26 \\
\hline Zilina &. &. &. &. & 11 & 15 & 19 & 23 \\
\hline Poprad &. &. &. &. &. &. & 7 & 11 \\
\hline
\end{tabular}

Revenues after the change of rates: $€ 6,410.4$

Profit after the change of rates: $€ 267.67$

The carrier may also modify tariff rates with respect to each day of the week according to the occupancy of the train, recapitulation is show in Table 10. From the analysis it is clear that if about 500 people travel in one train from Bratislava to Kosice, the price for transport would be around $€ 13$ per one person.

\section{Conclusion}

Own costs in the railway sector are similarly as in the case of other modes of transport influenced by external and internal factors. Among the external factors we can include mainly fees for the use of railway infrastructure, energy prices, rental (lease payments) of locomotives, carriages and so on. Good predictions on the number of transported passengers and the occupancy of seats on the train are necessary in order to eliminate the risk from unoccupied capacity of the train and then it is possible to propose the tariff which can effectively eliminate this risk. The carrier may also modify tariff rates with respect to each day of the week according to the occupancy of the train. From the analysis it is clear that if about 500 people travel in one train from Bratislava to Kosice, the price for transport would be around $€ 13$.

The ticket price for the session BA - KE with the state carrier is currently $€ 18.76$ (full price, which is subsidised by 
Comparison of the Ticket Price on the Session BA - KE Table 10

\begin{tabular}{|c|c|c|c|c|c|c|c|c|c|}
\hline \multirow{11}{*}{ 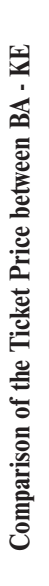 } & \multicolumn{9}{|c|}{ Own proposal } \\
\hline & \multicolumn{2}{|c|}{$100 \%$ occupancy } & \multicolumn{2}{|c|}{$80 \%$ occupancy } & \multicolumn{2}{|c|}{$60 \%$ occupancy } & \multicolumn{3}{|c|}{$40 \%$ occupancy } \\
\hline & 1. class & 2. class & 1. class & 2. class & 1. class & 2. class & 1. class & \multicolumn{2}{|c|}{ 2. class } \\
\hline & 17 & 13 & 20 & 16 & 25 & 21 & 35 & \multicolumn{2}{|c|}{31} \\
\hline & \multicolumn{9}{|c|}{ RegioJet } \\
\hline & \multicolumn{3}{|c|}{ Purchase of a ticket one day in advance ${ }^{*}$} & \multicolumn{3}{|c|}{ Purchase of a ticket on Friday* } & \multicolumn{3}{|c|}{ Purchase of a ticket a week in advance* } \\
\hline & Standard & Relax & Business & Standard & Relax & Business & Standard & Relax & Business \\
\hline & $12.1-14$ & 15.9-18.7 & $20.6-25.3$ & $12.1-21.5$ & $15.9-28.1$ & $20.6-33.7$ & $12.1-14$ & 15.9-18.7 & $20.6-25.3$ \\
\hline & \multicolumn{9}{|c|}{ ZSSK, a.s. (state carrier) } \\
\hline & 2. class & $\begin{array}{c}\text { CLASIK } \\
\text { RAILPLUS }\end{array}$ & & & & & & & \\
\hline & 18.76 & 14.07 & & & & & & & \\
\hline
\end{tabular}

*Ticket price depends on the time of travel during the day (5:33 AM, 11:33 AM, 5:33 PM)

the state); private carrier RegioJet offers the price from $€ 12.1$ to $€ 33.7$ for this session, however this price depends on three factors (the day of ticket purchase, travel time and the class of a carriage). In our proposal, which takes into account the risk from unoccupied capacity of a train, the ticket price is dependent on the occupancy of the train. In the case of $40 \%$ occupancy of the train, the ticket price in own proposal is lower than the price level with a private carrier in the highest class during the rush hour. At formation of the tariff policy it is important to take into consideration the forecast of development of the number of passengers.

\section{Acknowledgements}

The paper is supported by the VEGA Agency under Project $1 / 0095 / 16$ "Assessment of the quality of connections on the transport network as a tool to enhance the competitiveness of public passenger transport systems"

\section{References}

[1] DVORAK, Z. et al.: Risk Management in Rail Transport, University of Pardubice, Institute of Jan Perner, $1^{\text {st }}$ ed., 2010, ISBN 978-8086530-71-0

[2] POLIAK, M., KRIZANOVA, A., SEMANOVA, S., GAJANOVA, L.: The Influence of Contract Form Choice of the Transport Services Ensuring on Performance Contracting Entity Requirement. Transport Problems = Problemy Transportu: Intern. Scientific J., vol. 9, No. 4, 2014, 153-161, ISSN 1896-0596

[3] GASPARIK, J., SIROKY, J., PECENY, L., HALAS, M.: Methodology for Assessing the Quality of Rail Connections on the Network. Communications - Scientific Letters of the University of Zilina, vol. 16, No. 2, 2014, 25-30. ISSN 1335-4205

[4] DOLINAYOVA, A., LOCH, M., KANIS, M.: Modelling the Influence of Wagon Technical Parameters on Variable Costs in Rail Freight Transport. Research in Transportation Economics, 2015, vol. 54, 33-40.

[5] STOPKA, O., SIMKOVA, I., KONECNY, V.: The Quality of Service in the Public Transport and Shipping Industry, Nase More, Dubrovnik: University of Dubrovnik, vol. 62, Special Issue, 2015, 126-130. ISSN 0469-6255

[6] NEDELIAKOVA, E., DOLINAYOVA, A., GASPARIK, J.: Methodology of Transport Regulation in the Slovak Republic, Periodica Polytechnica Transportation Engineering, vol. 38, No. 1, 2010, 37-43.

[7] MAJERCAK, J., KUDLAC, S., PANAK, M.: Sustainable and Economically Efficient Five-point Supply Chain Management. Proc. of $20^{\text {th }}$ intern. scientific conference Transport Means 2016, Kaunas University of Technology, Kaunas University of Technology, 2016. 65-70, ISSN 1822-296X.

[8] GASPARIK, J., GABOROVA, V., LUPTAK, V.: Process Portal for Railway Cargo Operator with CRM Support, Proc. of the $20^{\text {th }}$ intern. conference Transport Means 2016, October 5-7, 2016, Kaunas University of Technology, 2016, 245-249, ISSN 1822-296X.

[9] KENDRA, M.; Integration of Individual Car Transport and Public Passenger Transport in Cities, Proc. of OPT-i $2014-1^{\text {st }}$ intern. conference on Engineering and Applied Sciences Optimization, 2014, 1582-1592, ISBN: 978-960999946-5 
[10] Document about the determination of charges for access to railway infrastructure valid from December 2, 2010.

[11] Document about the determination of charges for access to railway infrastructure valid from 24 May 2012, No. 7, 2012, which amends the previous one.

[12] STOPKA, O., PONICKY, J., CHOVANCOVA, M., ZITRICKY, V.: Draft Method for Determining the Number of Checking Devices Utilized within the Regional Passenger Transport, Nase more, vol. 63, No. 3, 2016, 200-203, ISSN 0469-6255.

[13] LALINSKA, J., CAMAJ, J., NEDELIAKOVA, E.: Possibilities and Solutions of Compensation for Delay of Passenger Trains and Their Economic Impacts, Proc. of the $19^{\text {th }}$ intern. conference Transport Means 2015, October, 2015, Kaunas University of Technology, 2016, 729-733, ISSN 1822-296X. 